\title{
Correlation between the Bone Mineral Density and Stress on Femur around a Duetto SI Stem
}

\author{
Rina Sakai, ${ }^{1}$ Takeaki Yamamoto, ${ }^{2}$ Katsufumi Uchiyama, ${ }^{2}$ Kentaro Uchida, ${ }^{2}$ \\ Masaki Nakao, ${ }^{3}$ and Kiyoshi Mabuchi ${ }^{1}$ \\ ${ }^{1}$ Department of Medical Engineering and Technology, School of Allied Health Sciences, Kitasato University, \\ 1-15-1 Kitasato, Minami Ku, Sagamihara, Kanagawa 252-0329, Japan \\ ${ }^{2}$ Department of Orthopaedic Surgery, School of Medicine, Kitasato University, Sagamihara, Kanagawa, Japan \\ ${ }^{3}$ Graduate School of Medical Sciences, Kitasato University, Sagamihara, Kanagawa, Japan
}

Correspondence should be addressed to Rina Sakai; rinax@kitasato-u.ac.jp

Received 19 April 2014; Revised 10 June 2014; Accepted 12 June 2014; Published 26 June 2014

Academic Editor: Ali Hosseini

Copyright (C) 2014 Rina Sakai et al. This is an open access article distributed under the Creative Commons Attribution License, which permits unrestricted use, distribution, and reproduction in any medium, provided the original work is properly cited.

In cementless stem fixation, BMD reduction around the stem is of concern because it may cause loosening. This BMD reduction is assumed to be caused by stem implantation-induced alteration of the physiological feedback system, which may cause stress shielding and result in loosening, but the causal relationship has not been clarified. In this study, using a Duetto SI stem, we investigated the correlation between the postoperative BMD around the stem and stress. In patients who underwent their first THA at the orthopedic department of our university, the BMD was measured using DEXA, and FEA was performed with an equivalent time course. Time-course changes in the BMD, von Mises stress, and triaxial stress in Gruen zones 1 through 7 were calculated from those measured at 2 weeks and 5 months after surgery. The BMD and von Mises stress showed a bidirectional correlation when Gruen's classification was plotted on the horizontal axis. An increase in stress loaded on bone was assumed to be a factor increasing the BMD. The Duetto SI stem was fixed on the distal side, suggesting its stable fixation. BMD measurement and FEA were useful for quantification of the bone dynamics around the stem from an early phase.

\section{Introduction}

As a complication of total hip arthroplasty (THA), loosening around the hip stem may occur [1]. After cementless fixation, a decrease in the bone mineral density (BMD) around the stem may induce loosening, presenting a problem. Bone has a physiological feedback mechanism by which stress is detected, and the bone mass is controlled to maintain an equilibrium with the bone strength [2]. Hip prosthesis stem implantation can alter this physiological feedback system, reducing the $\mathrm{BMD}$. As a substitute for a marked decrease in the BMD, stress shielding, a term derived from the engineering field, is used $[3,4]$. Stress shielding in the physiological feedback mechanism may reduce stress applied to bone, reducing the BMD. However, their causal relationship has not been clarified.

The Duetto SI stem (Cgdb, Italy) has been used for osteoarthritis of the hip associated with congenital acetabular dysplasia by the Department of Orthopedics in our university. Many hip stems previously sold in Japan did not fit the skeleton of Japanese or the deformed bone with osteoarthritis. Thus, the Duetto SI stem was developed as a stem fitting the skeleton of Japanese by Professor Itoman while maintaining the characteristic: conservation of cancellous bone and bone marrow. Therefore, using the Duetto SI stem, we evaluated the correlation between the postoperative BMD and stress around the stem. The time course of the BMD was evaluated in patients who underwent THA in the orthopedic department of our university, and numerical simulation was concurrently performed using a time course equivalent to the clinical time course. Proximal bone loss around a stem, prepared based on the same fixation principle as that of the Duetto SI stem, has been reported [5]. DEXA has been reported to allow the quantitative evaluation of slight BMD changes around the stem after THA [6-8].

Therefore, using the Duetto SI stem, we evaluated the correlation between the postoperative BMD and stress around 
the stem. The time course of BMD was evaluated in patients who underwent THA in the orthopedic department of our university, and numerical simulation was concurrently performed using a time course equivalent to the clinical time course. The prevention and improvement of stress shielding, which may reduce the fixation force by evaluating the bone and stress states around the stem are indispensable for improving the postoperative results of THA.

\section{Materials and Methods}

This study was approved by the Ethics Committee, Kitasato University School of Medicine (2010-008). We evaluated 35 patients who underwent THA using a Duetto SI stem in the orthopedic department of our university between May 2007 and October 2008 and could be followed up for 5 months or more. The mean age at the time of the operation was 62 years. The underlying disease was coxarthrosis in 30 patients, rheumatoid arthritis in 1, femoral head necrosis in 3 , and fracture in 1 . The $\operatorname{BMD}\left(\mathrm{g} / \mathrm{cm}^{2}\right)$ was measured 2 weeks and 5 months after the operation employing an X-ray BMD measurement system (DISCOVERY, Hologic, Inc., USA) using dual energy X-ray absorptiometry (DEXA). Time-course changes in the BMD in zones 1-7 according to Gruen's Classification were calculated [9].

The Duetto SI stem (Cgdb, Italy) evaluated in this study was designed to preserve cancellous bone and bone marrow and minimize blood flow impairment in the medullary cavity and has a thin rectangular cross-sectional shape from the neck to the distal end (Figure 1). Since this design is firmly fixed, biting the cortical bone of the femur, it shows superior rotational fixation, which is closely involved in the loosening of cementless stems. The medial curvature of the proximal stem is designed to fit the femoral morphology. The material is titanium alloy (Ti6Al4V), and the stem surface is processed to produce 6-micron roughness in order to induce bone ongrowth.

A model for finite element analysis (FEA) that has 8node hexahedral isoparametric elements was constructed by altering the shape of the existing hip prosthesis stem [10]. The femoral model was constructed by automatic mesh formation based on CT images of a right femur of a 78-yearold male (OA). The complex system analysis model, which is composed of the stem, cortical bone, and cancellous bone, consisted of 3,087 elements and 4,440 nodes. FE models with about 3,000, 5,000, and 10,000 elements were prepared. Since no marked change was noted in stress values, the model with about 3,000 elements was adopted because the analytical time was shorter. A study using the same model has been reported, in which a mechanical test and analysis were performed to calculate the rotatory displacement of the Duetto SI stem, and the results obtained by the test and analysis were equivalent [11]. Material properties were defined as the combination of the mass density $\left(\mathrm{g} / \mathrm{cm}^{3}\right)$, elastic modulus $(\mathrm{Pa})$, and Poisson's ratio [12]. The mass density was determined as $4.5 \mathrm{~g} / \mathrm{cm}^{3}$ for the stem, $2.3 \mathrm{~g} / \mathrm{cm}^{3}$ for cortical bone, and $1.9 \mathrm{~g} / \mathrm{cm}^{3}$ for cancellous bone by substituting values of experimental measurements. Based on the values in the literature,

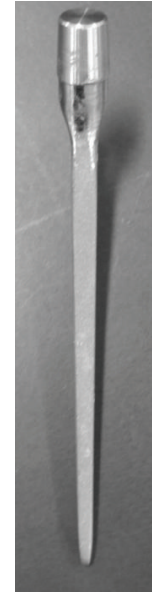

(a)

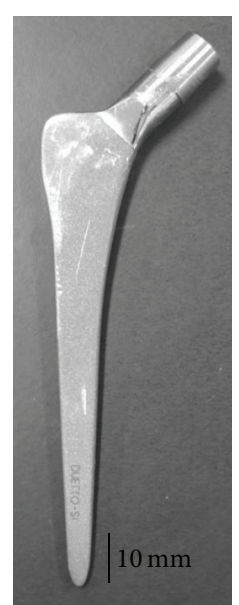

(b)
FIgURE 1: Duetto SI stem with a thin cross-sectional shape. (a) Medial side. (b) Arterial side. The stem surface was processed to produce 6-micron roughness in order to induce bone ongrowth.

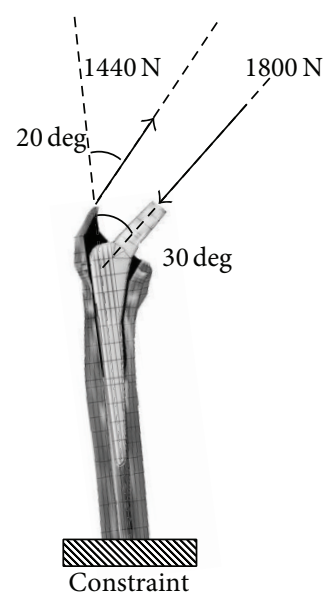

FIgURE 2: Loading and constraint conditions of FE model. A resultant force of $1,800 \mathrm{~N}$ was applied to the head at an angle of $30^{\circ}$ along the long axis. An abductor force of $1,440 \mathrm{~N}$ was applied from the greater trochanter along the long axis at an angle of $20^{\circ}$. Hatched squares represent restrained regions.

the elastic modulus and Poisson's ratio were set at $110 \mathrm{GPa}$ and 0.29 , respectively, for the stem, $15.5 \mathrm{GPa}$ and 0.30 for cortical bone, and $1.00 \mathrm{GPa}$ and 0.33 for cancellous bone [13].

For analysis, Endeavor Pro-4500 (EPSON, Japan) was used as hardware and finite element analysis LS-DYNA Ver.971 (Terrabyte, Japan) as software. The distal end of the femur was constrained in all directions. Based on the ISO7206, a 1,800 $\mathrm{N}$ load was applied to the femoral head, and the abduction force was set at 1,440 N [14, 15] (Figure 2). Concerning contact conditions, the coefficient of friction between the cortical bone and the stem was assumed to be 0.3 , and automatic control with a consideration of sliding was used $[16,17]$. The von Mises stresses and stresses in the 3 axis directions 2 weeks and 5 months after the operation were analyzed, and each value at the middle point of each zone 


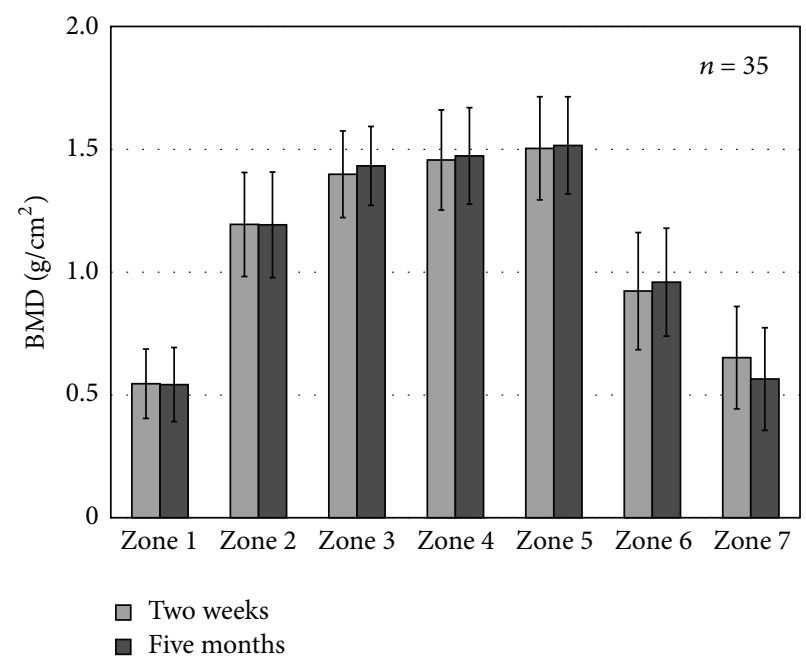

(a)

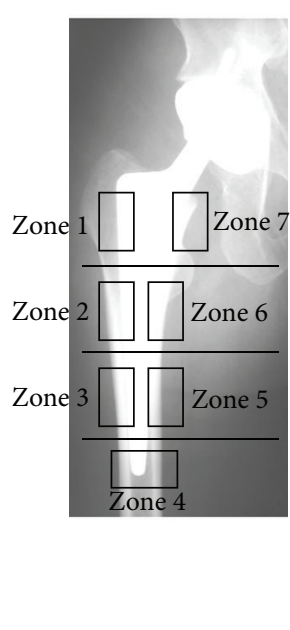

(b)

Figure 3: BMD measured by DEXA. (a) BMD values in each zone 2 weeks and 5 months after the operation. (b) X-ray image and Gruen's zone classification.

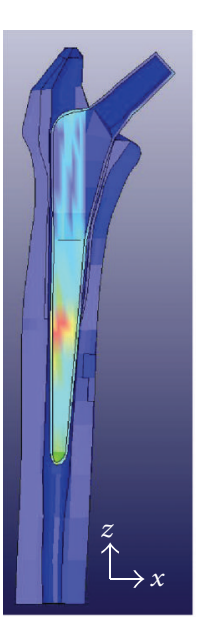

(a)

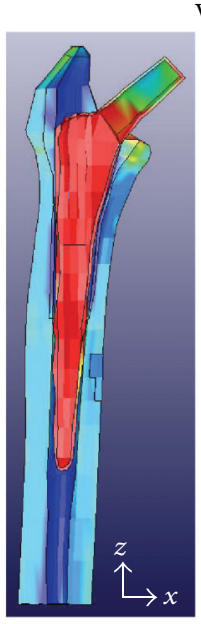

(b)

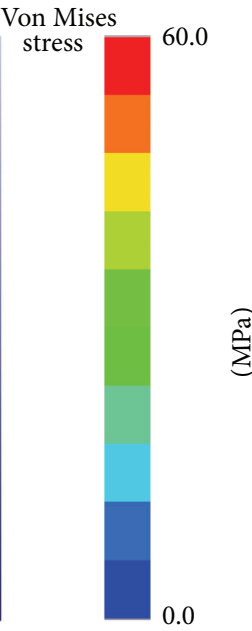

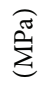

Figure 4: Von Mises stress distribution analyzed by finite element methods. (a) Two weeks. (b) Five months.

was calculated. The stress value according to the zone in bone around the stem was clarified, and its correlation with the BMD was evaluated.

\section{Results}

At both 2 weeks and 5 months after the operation, the BMD was about $0.5 \mathrm{~g} / \mathrm{cm}^{2}$ in the proximal zones (zones 1 and 7) and about $1.4 \mathrm{~g} / \mathrm{cm}^{2}$ in the distal zones (zones 3,4 , and 5) of the stem (Figure 3).

The von Mises stress obtained by FEA 2 weeks after the operation was $9 \mathrm{MPa}$ in zones 3 and 5 and $8 \mathrm{MPa}$ in zone 4 of the femur, and that 5 months after the operation was $20 \mathrm{MPa}$ in zone 4 of the femur (Figure 4). The von Mises stress 5 months after the operation was $4 \mathrm{MPa}$ in zone 7 and $\geq 8 \mathrm{MPa}$ in the other zones (Figure 5). The von Mises stress 2 weeks after the operation was $\geq 8 \mathrm{MPa}$ in zones 3 , 4 , and 5 and that 5 months after the operation was $20 \mathrm{MPa}$ in zone 4. The peak BMD was observed in zone 5, and the peak von Mises stress was observed in zone 3 after 2 weeks and in zone 4 after 5 months. When Gruen's classification was plotted on the horizontal axis, a bidirectional correlation (bell-shaped symmetrical distribution) between the BMD and von Mises stress was observed.

Time series data on stress values in the 3 axis directions in each zone obtained by FEA from immediately to 5 months after the operation showed lower absolute stress values after 5 months than after 2 weeks in some zones (Figure 6). Based on the trend in time series data, the absolute stress value in the $y$ axis direction tended to increase in zones 2 and 4 compared with the other zones. Similarly, in the $z$-axis direction as a sinking direction, the absolute stress value tended to increase in zone 2.

\section{Discussion}

BMD evaluation after cementless THA has frequently been performed [18, 19]. Munting et al. quantitatively measured the BMD after cementless THA in 32 joints of 31 patients during a 6-year postoperative period [20]. Kröger et al. proposed that BMD evaluation should be performed early after the operation [21]. Therefore, we initiated BMD evaluation 2 weeks after the operation. In this study, to clarify bond dynamics around the stem, FEA was performed in combination with BMD measurement by DEXA using an equivalent time course. There have been no studies comparing the BMD obtained by DEXA and the stress obtained by the analysis.

Bone constantly undergoes remodeling, which is the continual cycle of the resorption of hard bone and bone formation to replenish lost areas. Engh and Massin reported 


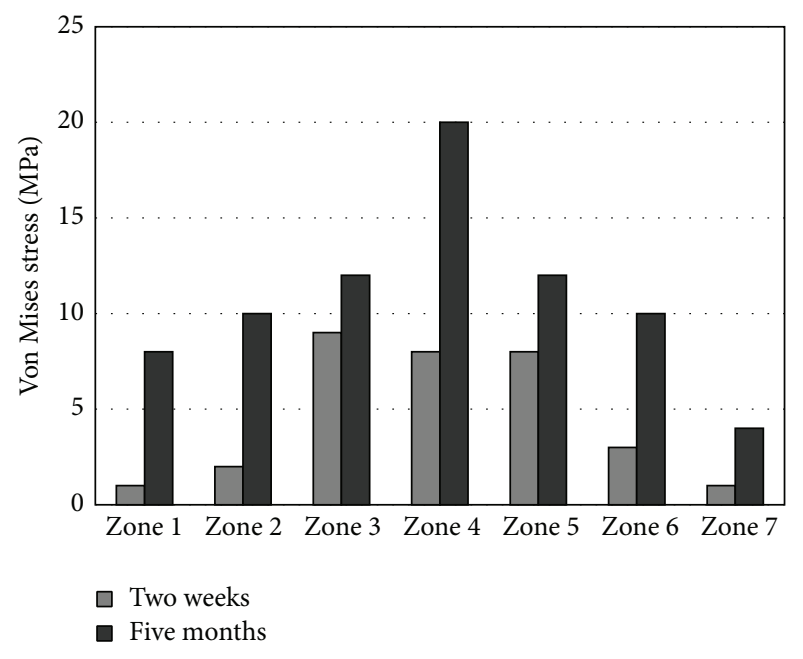

(a)

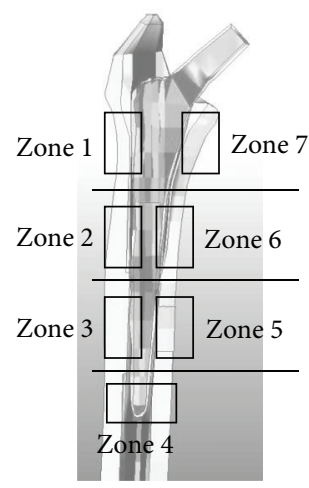

(b)

Figure 5: Von Mises stress analyzed by finite element methods. (a) Von Mises stress values in each zone 2 weeks and 5 months after the operation. (b) Finite element model and Gruen's zone classification.

that an increase in the BMD is a direct sign of bone formation [22]. Huiskes et al. reported that an increase in stress promotes bone remodeling [23]. When Gruen's classification was plotted on the horizontal axis, the BMD and von Mises stress around the Duetto SI stem showed peaks in the distal area, showing a bidirectional correlation. The results of this study supported the report by Engh and Massin and the proposal by Huiskes et al. Comparison between 2 weeks and 5 months after the operation showed increases in the stress values in the 3 axis directions in many zones with time after the operation. Therefore, an increase in stress on bone may be a factor associated with an increase in the BMD.

The stress value around the Duetto SI stem after 2 weeks was low in the $y$-axis direction. This may have been because of the absence of contact with cortical bone in the anteroposterior direction due to the thin cross-sectional shape as a characteristic of European stems. This gap is useful for preventing blood flow impairment. There was high stress in the $z$-axis direction as the sinking direction, and a distribution indicating a surface force in the axial direction in all zones was observed. The BMD did not differ between 2 weeks and 5 months after the operation, but the stress values in the 3 axis directions were slightly higher after 5 months than after 2 weeks. This may have been because surface force in the axial direction and circumferential stress occurred due to stem sinking into the medullary cavity. There have also been many clinical reports of sinking using other stems [24].

Using another Zweymueller type of stem, stress shielding in the proximal area was reported [25]. Using the Duetto SI stem, since stress based on MPa values was observed in each zone of bone and the entire stem, stress shielding was unlikely. Engh and Massin described that the stem tip is stable when the BMD is high in zone 4 [22]. Thus, the fixation force of the Duetto SI stem may be obtained in the distal area, which suggests stable fixation.
Concerning the BMD after cementless THA, Nakamura observed 25 joints of 21 patients who underwent an operation using an Omniflex stem from 1 month until 1 year after the operation and reported low BMD values in zones 1 and 7 [26]. The results of this study were consistent with theirs. Due to constant metabolism-associated changes in the BMD, the observation period should be increased. In this study, since FEA was concurrently performed using an equivalent time course, the observation period was 5 months due to the limit of machine specifications. In the future, a long-term followup of the course of the BMD will be necessary. In addition, to obtain more reliable data, the results of analysis should be evaluated using statistical methods with a consideration of errors. Regarding the limitations of this study, since von Mises stress is affected by the bone modulus, it is necessary to prepare several models by changing the bone modulus. Simplified cortical and cancellous bones were used, but more accurate investigation is possible using a model to which tendons, ligaments, and muscles are added.

Evaluation of the BMD and stress around the Duetto SI stem revealed the following.

(1) There was a bidirectional correlation between the BMD and stress when Gruen's classification was plotted on the horizontal axis.

(2) The Duetto SI stem was fixed on the distal side, which suggested stable fixation.

(3) BMD evaluation and FEA were useful for quantitatively clarifying bone kinetics around the stem.

\section{Conflict of Interests}

The authors did not and will not receive any benefit or funding from any commercial party related directly or indirectly to the subject of this paper. 

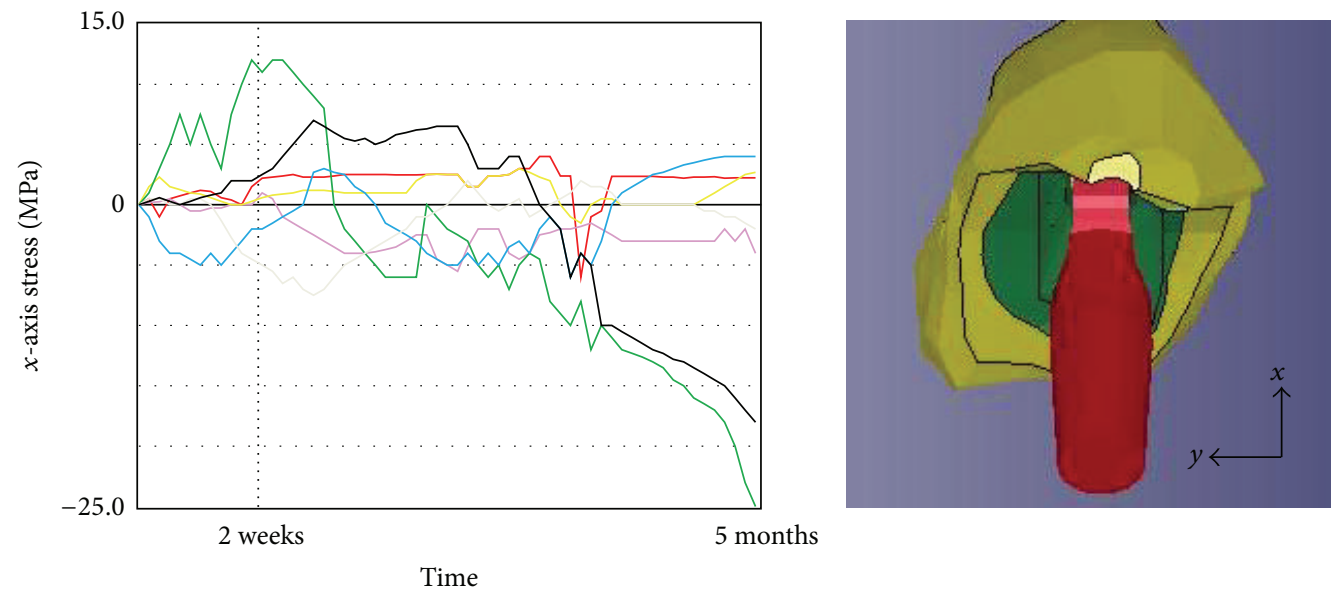

(a)
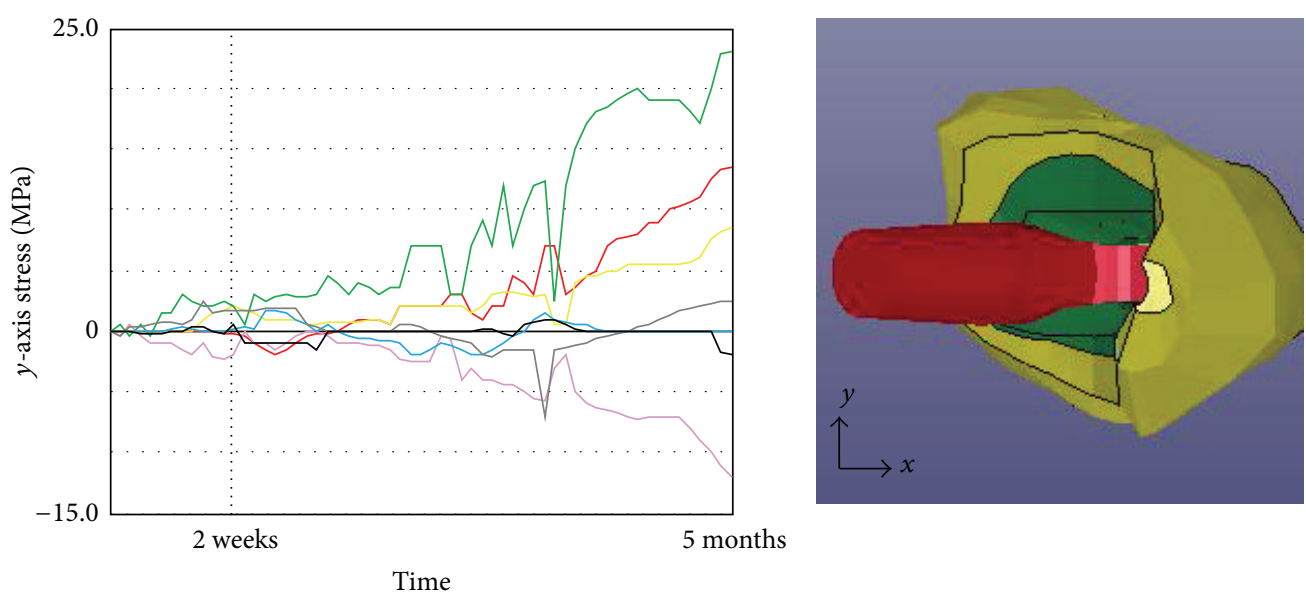

(b)
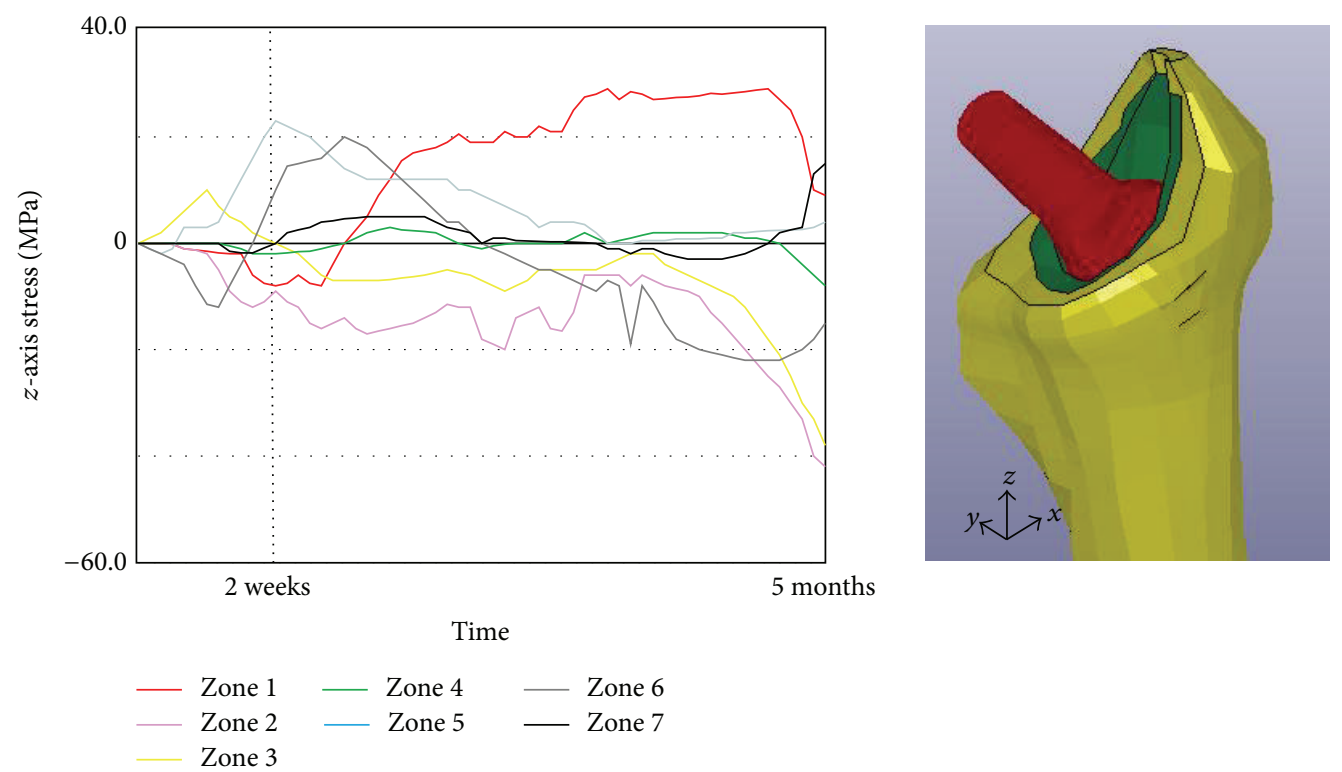

(c)

FIgURE 6: Time series data on stress in the 3 axis directions in each zone obtained by FEM immediately until 5 months after the operation. (a) $x$-axis (medial-lateral) direction. (b) $y$-axis (anterior-posterior) direction. (c) $z$-axis (sinking) direction. 


\section{References}

[1] T. W. Phillips, L. T. Nguyen, and S. D. Munro, "Loosening of cementless femoral stems: a biomechanical analysis of immediate fixation with loading vertical, femur horizontal," Journal of Biomechanics, vol. 24, no. 1, pp. 37-48, 1991.

[2] H. M. Frost, "Bone's mechanostat: a 2003," The Anatomical Record A: Discoveries in Molecular, Cellular, and Evolutionary Biology, vol. 275, no. 2, pp. 1081-1101, 2003.

[3] E. Garcia-Cimbrelo, E. Garcia-Rey, A. Cruz-Pardos, and R. Madero, "Stress-shielding of the proximal femur using an extensively porous-coated femoral component without allograft in revision surgery: a 5- to 17-year follow-up study," Journal of Bone and Joint Surgery B, vol. 92, no. 10, pp. 1363-1369, 2010.

[4] M. G. Joshi, S. G. Advani, F. Miller, and M. H. Santare, "Analysis of a femoral hip prosthesis designed to reduce stress shielding," Journal of Biomechanics, vol. 33, no. 12, pp. 1655-1662, 2000.

[5] E. Garcia-Cimbrelo, A. Cruz-Pardos, R. Madero, and M. Ortega-Andreu, "Total hip arthroplasty with use of the cementless Zweymüller Alloclassic system. A ten to thirteen-year follow-up study," Journal of Bone and Joint Surgery A, vol. 85, no. 2, pp. 296-303, 2003.

[6] K. Yamaguchi, K. Masuhara, S. Yamasaki, and T. Fuji, "Efficacy of different dosing schedules of etidronate for stress shielding after cementless total hip arthroplasty," Journal of Orthopaedic Science, vol. 10, no. 1, pp. 32-36, 2005.

[7] B. Cohen and N. Rushton, "Accuracy of dexa measurement of bone mineral density after total hip arthroplasty," Journal of Bone and Joint Surgery B, vol. 77, no. 3, pp. 479-483, 1995.

[8] C. R. Wilson, I. Fogelman, G. M. Blake, and A. Rodin, "The effect of positioning on dual energy X-ray bone densitometry of the proximal femur," Bone and Mineral, vol. 13, no. 1, pp. 6975, 1991.

[9] T. A. Gruen, G. M. McNeice, and H. C. Amstutz, "Modes of failure' of cemented stem-type femoral components. A radiographic analysis of loosening," Clinical Orthopaedics and Related Research, vol. 141, pp. 17-27, 1979.

[10] R. Sakai, Y. Sato, M. Itoman, and K. Mabuchi, "Initial fixation of a finite element model of an AI-Hip cementless stem evaluated by micromotion and stress," Journal of Orthopaedic Science, vol. 15, no. 1, pp. 132-139, 2010.

[11] R. Sakai, A. Iwama, M. Itoman, and K. Mabuchi, "Rotational stability based on displacements obtained by simulation and measurement when torsion loading is applied to hip stems," Journal of Orthopaedic Science, vol. 13, no. 3, pp. 248-254, 2008.

[12] J. H. Keyak, I. Y. Lee, and H. B. Skinner, "Correlations between orthogonal mechanical properties and density of trabecular bone: use of different densitometric measures," Journal of Biomedical Materials Research, vol. 28, no. 11, pp. 1329-1336, 1994.

[13] P. M. Cattaneo, M. Dalstra, and L. H. Frich, "A threedimensional finite element model from computed tomography data: a semi-automated method," Proceedings of the Institution of Mechanical Engineers H, vol. 245, pp. 203-245, 2001.

[14] D. T. Davy, G. M. Kotzar, R. H. Brown et al., "Telemetric force measurements across the hip after total arthroplasty," Journal of Bone and Joint Surgery A, vol. 70, no. 1, pp. 45-50, 1988.

[15] P. B. Chang, B. J. Williams, K. S. B. Bhalla et al., "Design and analysis of robust total joint replacements: finite element model experiments with environmental variables," Journal of Biomechanical Engineering, vol. 123, no. 3, pp. 239-246, 2001.
[16] W. R. Taylor, E. Roland, H. Ploeg et al., "Determination of orthotropic bone elastic constants using FEA and modal analysis," Journal of Biomechanics, vol. 35, no. 6, pp. 767-773, 2002.

[17] N. Nuño and M. Amabili, "Modelling debonded stem-cement interface for hip implants: effect of residual stresses," Clinical Biomechanics, vol. 17, no. 1, pp. 41-48, 2002.

[18] H. S. Bodén, O. G. Sköldenberg, M. O. Salemyr, H. Lundberg, and P. Y. Adolphson, "Continuous bone loss around a tapered uncemented femoral stem: a long-term evaluation with DEXA," Acta Orthopaedica, vol. 77, no. 6, pp. 877-885, 2006.

[19] M. Galli, A. Leone, F. C. Tamburrelli, T. Pirronti, and A. G. Aulisa, "Periprosthetic mineralization changes around femoral stems: a prospective 12-month study with DEXA," Skeletal Radiology, vol. 37, no. 8, pp. 723-729, 2008.

[20] E. Munting, P. Smitz, N. Van Sante, C. N. De Deuxchaisnes, A. Vincent, and J.-P. Devogelaer, "Effect of a stemless femoral implant for total hip arthroplasty on the bone mineral density of the proximal femur: a prospective longitudinal study," The Journal of Arthroplasty, vol. 12, no. 4, pp. 373-379, 1997.

[21] H. Kröger, H. Miettinen, I. Arnala, E. Koski, N. Rushton, and O. Suomalainen, "Evaluation of periprosthetic bone using dualenergy $\mathrm{x}$-ray absorptiometry: precision of the method and effect of operation on bone mineral density," Journal of Bone and Mineral Research, vol. 11, no. 10, pp. 1526-1530, 1996.

[22] C. A. Engh and P. Massin, "Cementless total hip arthroplaty using the anatomic medullary locking stem. Results using a survivorship analysis," Clinical Orthopaedics and Related Research, no. 249, pp. 141-158, 1989.

[23] R. Huiskes, H. Weinans, H. J. Grootenboer, M. Dalstra, B. Fudala, and T. J. Slooff, "Adaptive bone-remodeling theory applied to prosthetic-design analysis," Journal of Biomechanics, vol. 20, no. 11-12, pp. 1135-1150, 1987.

[24] M. Paterson, P. Fulford, and R. Denham, "Loosening of the femoral component after total hip replacement. The thin black line and the sinking hip," Journal of Bone and Joint Surgery B, vol. 68 , no. 3, pp. 392-397, 1986.

[25] P. Korovessis, P. Droutsas, G. Piperos, A. Michael, A. Baikousis, and M. Stamatakis, "Course of bone mineral content changes around cementless Zweymueller total hip arthroplasty: a 4-year follow-up study," Archives of Orthopaedic and Trauma Surgery, vol. 116, no. 1-2, pp. 60-65, 1997.

[26] K. Nakamura, "Measurement of periprosthetic bone mineral density after cementless hip arthroplasty by dual energy X-ray absorptiomeiry: longitudinal and cross-sectional evaluation," Journal of Orthopaedic Science, vol. 1, no. 2, pp. 113-122, 1996. 


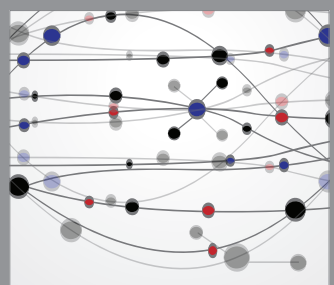

The Scientific World Journal
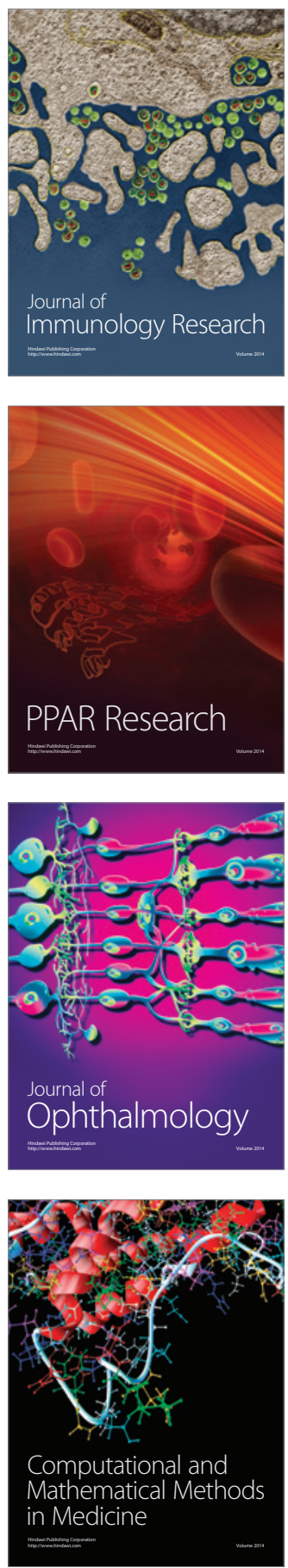

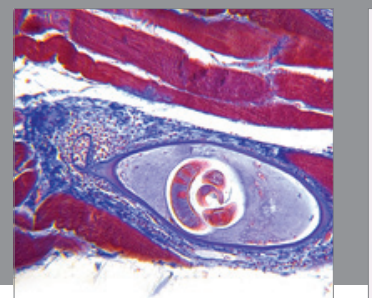

Gastroenterology

Research and Practice
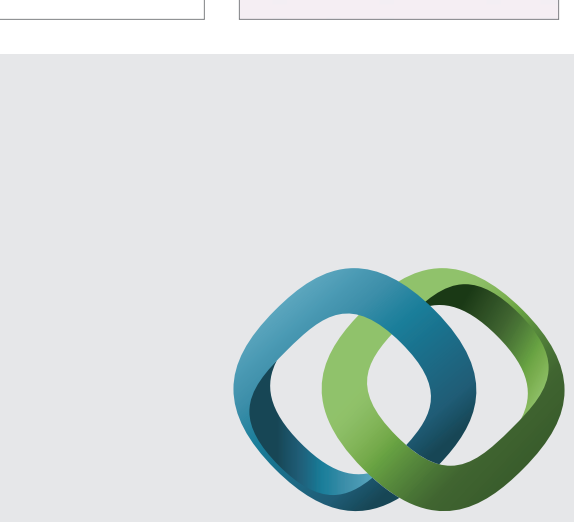

\section{Hindawi}

Submit your manuscripts at

http://www.hindawi.com
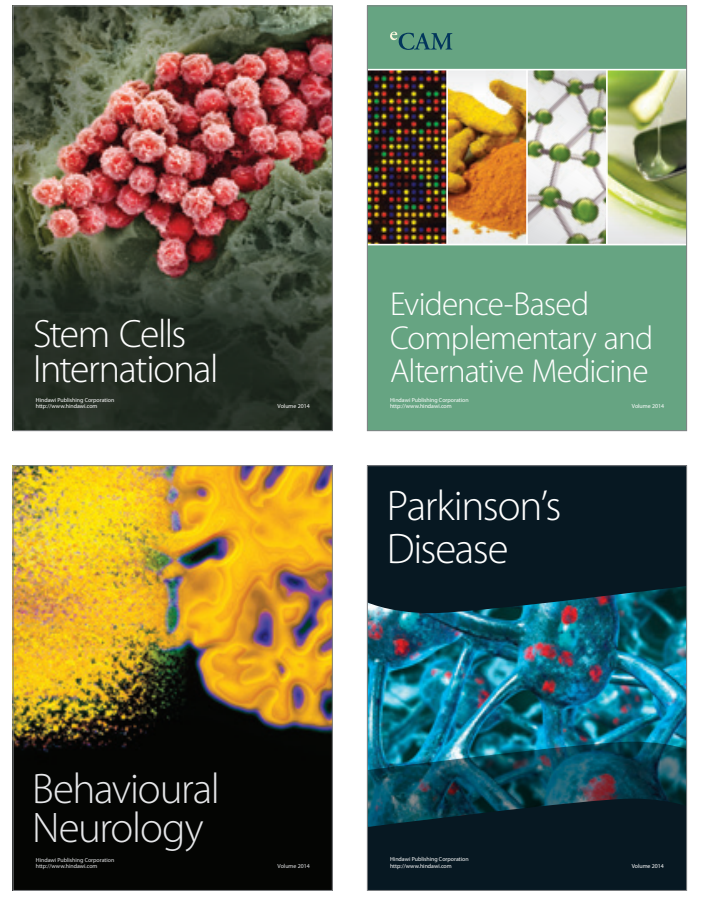
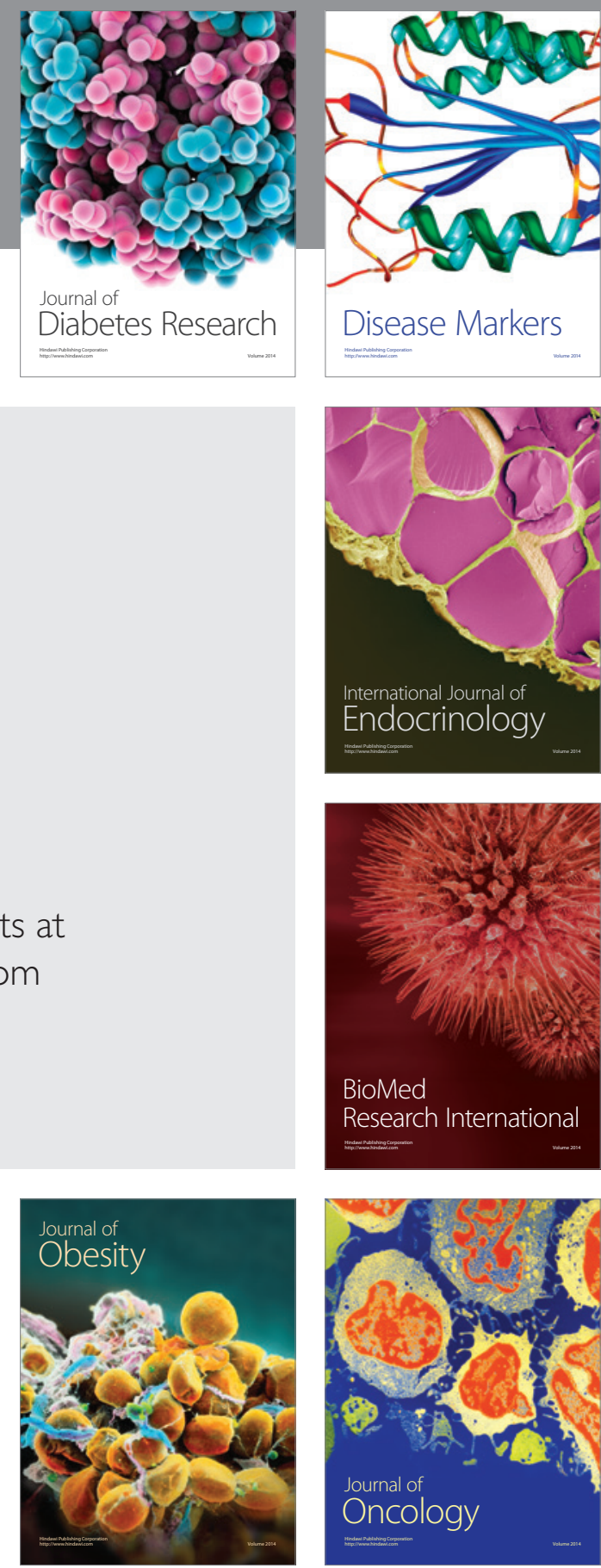

Disease Markers
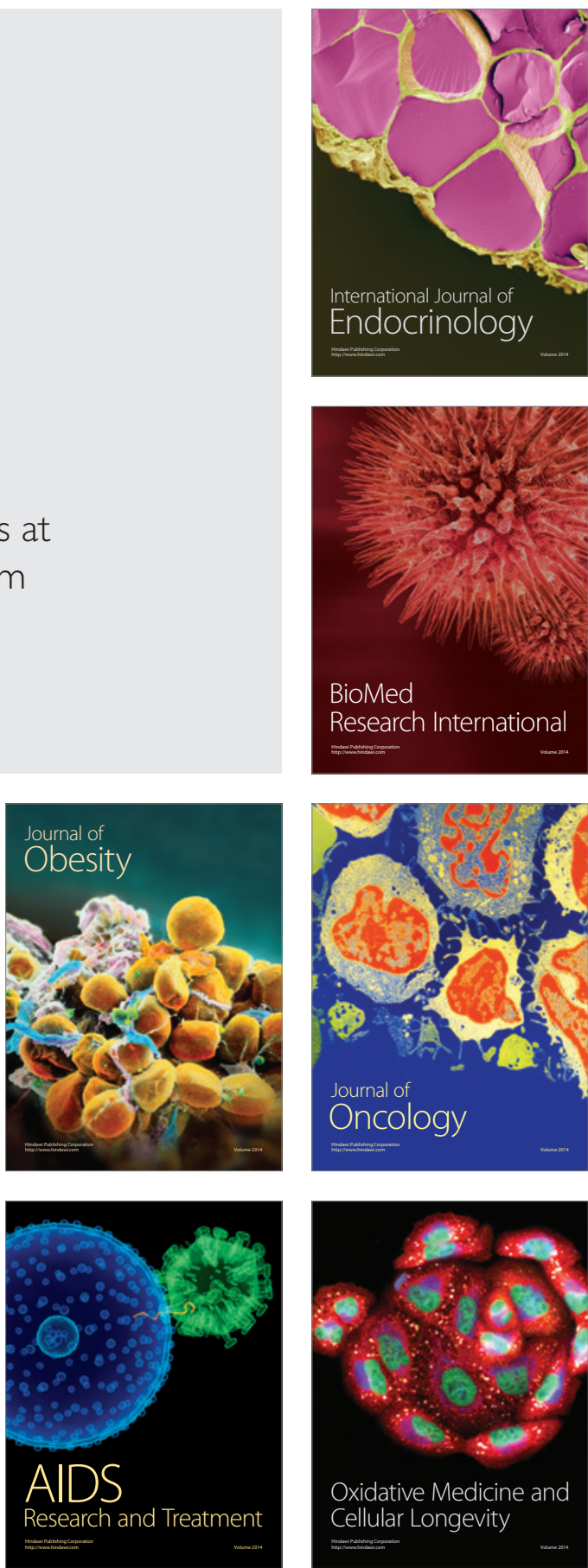